OPEN ACCESS

Edited by:

Ann Valerie Hedrick,

University of California, Davis,

United States

Reviewed by:

Paul Carl Sikkel,

Arkansas State University,

United States

Adam Crane,

University of Saskatchewan, Canada

*Correspondence:

Hope Klug

hope-klug@utc.edu

Specialty section

This article was submitted to Behavioral and Evolutionary Ecology,

a section of the journal

Frontiers in Ecology and Evolution

Received: 06 June 2018 Accepted: 28 November 2018 Published: 18 December 2018

Citation:

Farnsley S, Kuhajda B, George A and Klug H (2018) Learning to Overcome a Lack of Evolutionary History: Can an Endangered Fish Learn to Fear an Introduced Predator?

Front. Ecol. Evol. 6:214

doi: 10.3389/fevo.2018.00214

\section{Learning to Overcome a Lack of Evolutionary History: Can an Endangered Fish Learn to Fear an Introduced Predator?}

\author{
Sarah Farnsley ${ }^{1}$, Bernard Kuhajda ${ }^{2}$, Anna George ${ }^{2}$ and Hope Klug ${ }^{1,3 *}$ \\ ${ }^{1}$ Department of Biology, Geology, \& Environmental Science, University of Tennessee at Chattanooga, Chattanooga, TN, \\ United States, ${ }^{2}$ Tennessee Aquarium Conservation Institute, Chattanooga, TN, United States, ${ }^{3}$ SimCenter, University of \\ Tennessee at Chattanooga, Chattanooga, TN, United States
}

Rapid environmental change has led to unprecedented rates of biodiversity loss. One source of rapid environmental change involves the introduction of non-native species. In many cases, lack of evolutionary history with introduced species means that native species lack adaptive responses to avoid predation by introduced species. Understanding how native species can persist with introduced species has been a major focus of biological research. In some cases, learning can allow native individuals to acclimate when faced with introduced species. However, we lack a comprehensive understanding of whether learning can allow individuals to overcome a lack of evolutionarily engrained behavior in relation to non-native species. Here, we illustrate that in some cases individuals can potentially learn to overcome a lack of evolutionarily engrained anti-predator behavior when faced with a novel predator and be conditioned to avoid predation. Specifically, by pairing an aversive stimulus with the presence of an introduced, novel fish predator and measuring behavioral and survival effects, we demonstrate that an endangered fish species, the Barrens Topminnow (BTM), Fundulus julisia, can learn to exhibit anti-predator behavior toward an introduced predator. This anti-predator behavior potentially increases survival in the wild. In addition, our findings suggest that BTM adjust their behavior in response to chondroitin sulfate, suggesting that this chemical might function as an alarm cue in this species.

Keywords: learning, invasive species, adaptation, acclimation, Barrens Topminnow

\section{INTRODUCTION}

Human activity is devastating many natural populations and leading to drastic biodiversity loss worldwide (Novacek, 2001; Novacek and Cleland, 2001; Halpern et al., 2008; Barnosky et al., 2011; Wong and Candolin, 2015). One of the most pressing conservation concerns associated with human activity is the introduction of non-native species (Vitousek et al., 1997). When nonnative species are introduced to a community, native species typically have no evolutionary history with the introduced species and lack adaptations to effectively persist with the introduced species (Pimentel et al., 2005; Schlaepfer et al., 2005; Robertson et al., 2013; Wong and Candolin, 2015).

Various conservation efforts have been proposed to mitigate the effects of introduced species on native populations (reviewed in Novacek and Cleland, 2001). For example, some authors 
have proposed artificially creating selective pressures on native individuals in order to initiate the evolution of adaptive behaviors (Schlaepfer et al., 2005). However, this may only be effective for species with small home ranges and sufficient genetic variation (Schlaepfer et al., 2005). Likewise, manipulating the genetic composition of native populations to increase their rate of evolution might allow native populations to effectively adapt to the challenges created by non-native species (Schlaepfer et al., 2005). Such an approach, though, likely requires knowledge of the underlying genetics of adaptive strategies. Additionally, removal of non-native species can effectively mitigate the effects of introduced species on native individuals, but complete removal is often improbable once invasive populations are established (Mooney and Hobbs, 2000).

In addition to the approaches discussed above, mitigating the effects of introduced species on native populations may require an integrative approach that incorporates knowledge from behavioral ecology, learning and cognition, evolution, and ecology (Buchholz, 2007; Greggor et al., 2014). Several authors have highlighted the importance of learning, cognition, and behavioral plasticity in conservation (Greggor et al., 2014; Wong and Candolin, 2015). Indeed, there is evidence that, in some cases, individuals can learn to alter their behavior in response to novel ecological challenges, including novel predators (Kiesecker and Blaustein, 1997; Mirza and Chivers, 2000, 2003; Gazdewich and Chivers, 2002; Shier and Owings, 2006) or novel toxic prey (Phillips and Shine, 2006; O'Donnell et al., 2010). Learning may even benefit the entire population if conditioned behavior can be horizontally transmitted (Sih et al., 2011). For example, naïve damselfish, Acanthochromis polyacanthus, have been shown to respond to a novel predator after observing the behavior of experienced members of the same species that were previously conditioned with chemical alarm cues to recognize a predator (Manassa and McCormick, 2012).

Additional research is needed to more fully understand the role that learning plays in mitigating the effects of introduced species on native populations. In particular, relatively few studies have focused on whether: (1) conditioning and learning, in particular, can allow endangered species to adaptively modify their response to an introduced predator and (2) individuals can effectively learn during early life-history stages (e.g., during the juvenile stage). This is particularly important, as endangered species tend to have characteristics that make them less likely to acclimate to novel environmental challenges (Kotiaho et al., 2005), and populations are expected to be more likely to recover from the detrimental effects of introduced species if individuals of relatively early life-history stages learn adaptive behavior, as this would be expected to lead to greater numbers of breeding adults.

To enhance our understanding of how learning can be used to mitigate detrimental effects of introduced species, we explored whether juveniles of an endangered fish species can learn to avoid an introduced predator. We focused on the Barrens Topminnow (BTM), Fundulus julisia, a freshwater fish that is endemic to the Barrens Plateau region of Tennessee. As of 2015, only three natural populations of BTM were known to exist (Bettoli, 2015). Despite extensive hatchery-based rearing and reintroduction efforts and habitat restoration programs, the BTM remains imperiled and has been identified as one of the most endangered fish species in eastern North America (Bettoli, 2015). The BTM is primarily endangered due to the introduction of the Western Mosquitofish (WMF), Gambusia affinis. The WMF preys on and harasses larval and juvenile BTMs, which leads to high BTM mortality (Bettoli, 2015). Historically, BTM have had limited experience with fish predators in general (Rakes, 1989), and as WMF is an introduced species, BTM have no evolutionary history with this predator specifically. The lack of experience with WMF and fish predators in general has likely led to BTM having no evolutionarily engrained anti-predator response to WMF.

Given that fish learn through conditioning (Mirza and Chivers, 2000; Gazdewich and Chivers, 2002; Manassa and McCormick, 2012), we hypothesized that juvenile BTM could be conditioned (i.e., trained) to recognize WMF as a predator and respond with ecologically appropriate anti-predator behavior, which could in turn improve BTM survival.

\section{MATERIALS AND METHODS}

To assess the effectiveness of conditioning in mitigating the effects of an introduced predator, we used a potential alarm cue found in fish epidermal cells, chondroitin sulfate, that elicits a fear response in some fish species (Mathuru et al., 2012; Farnsley et al., 2016) to condition BTM to avoid predation and harassment by WMF. In Phase 1 of the study, we examined if $\mathrm{BTM}$ respond to chondroitin sulfate to verify that this substance can be used as an aversive stimulus in conditioning. The BTM did respond to chondroitin sulfate (described below), and in Phase II, we attempted to condition BTM individuals to associate WMF with potential danger by pairing the chondroitin sulfate with the visual presentation of WMF. We then evaluated the behavioral response of conditioned and non-conditioned BTM to the presentation of WMF. Given that escape behavior (increased movement and schooling, burying, freezing, leaping) is common among related fish species and has been observed during collection of BTM (Rakes, 1989), we hypothesized that behavior, such as increased activity or freezing could allow BTM to escape predation by WMF. Next, to explore the fitness benefits of conditioning, we preliminarily assessed the survival effects of conditioning following release of the BTMs into their natural habitat (Phase III). Finally, we conducted a small followup experiment to determine whether conditioning vs. only experience with WMF most likely elicited any behavioral changes that were observed in the previous phases of the study (Phase IV).

\section{Fish Acquisition and Maintenance}

We obtained juvenile BTMs propagated and reared in captivity from Conservation Fisheries Inc. in Knoxville, TN, an organization that breeds BTM for reintroduction. Given that BTM were bred in captivity, all BTM in our study lacked experience with WMF. All WMF were collected from a spring where BTM have previously been found, the Ramsey Barn site, and where BTM individuals from this experiment were to be subsequently released. This site is located on a cattle farm and consists of two pools, the lower measuring $100 \mathrm{~m}^{2}$ and the upper pool $432 \mathrm{~m}^{2}$ (Goldsworth and Bettoli, 2006). When not 
in use in experimental trials, fish of each species were housed in groups of 25 in $75.7 \mathrm{~L}$ aquaria at the University of Tennessee Chattanooga, fed live brine shrimp daily, and maintained on a 14:10 h light:dark cycle. Water temperature was maintained at $\sim 18^{\circ} \mathrm{C}$. All animal work was approved by the University of Tennessee at Chattanooga Institutional Animal Care and Use Committee (1017-HMK01).

\section{Phase I: Testing BTM Response to Chondroitin Sulfate}

To evaluate the effect of the potential alarm substance chondroitin sulfate (Mathuru et al., 2012; Farnsley et al., 2016) on BTM behavior, we conducted an experiment that consisted of two treatments: (1) exposure to chondroitin $(N=10)$ and (2) exposure to a control substance (distilled water) $(N=10)$. Each replicate began by randomly selecting one fish and placing it in a 37.85 L observation tank isolated from all other tanks (i.e., fish in the observation tank had no physical, visual, or chemical contact with other fish) and from the behavioral observer. Specifically, we performed observations from behind an opaque plastic barrier through eye slits and with the aid of mirrors positioned above the aquaria. This set-up allowed minimal exposure to any cues other than the substance added to the tank.

We allowed fish to acclimate for $1 \mathrm{~h}$. For $10 \mathrm{~min}$ following acclimation and prior to substance addition, we observed fish behavior and recorded movement (i.e., whether the fish was motionless or in motion). We focused on motion because change in movement patterns is indicative of anti-predator behavior in topwater prey species (Reed, 1969; Farnsley et al., 2016). After $10 \mathrm{~min}$, we added the substance (chondroitin or distilled water) through tubing that had previously been run into the tank. Preliminary studies in which dye was added to the tubing confirmed that this method led to the substance being dispersed throughout the tank within seconds. The control substance was $5 \mathrm{~mL}$ of distilled water. The chondroitin treatment consisted of $0.07 \mathrm{mg}$ of chondroitin (Sigma C4384) dissolved in $5 \mathrm{~mL}$ of distilled water. This concentration of chondroitin is consistent with levels used that elicited an alarm response in Zebrafish (Danio rerio) and Northern Studfish (Fundulus catenatus), a close relative of BTM (Mathuru et al., 2012; Farnsley et al., 2016). Another $10 \mathrm{~min}$ observational period followed substance addition, with the same behavior being assessed.

We used Univariate Analysis of Variance to examine the effect of chondroitin on the change in activity (i.e., change in the proportion of the time spent active). Treatment (chondroitin or distilled water) was a fixed factor with change in activity as the dependent variable. If BTM respond to the alarm cue chondroitin sulfate, we expected the change in activity to differ between our two treatments.

\section{Phase Ila: Conditioning BTM to Associate WMF With an Aversive Stimulus}

We isolated and observed tanks in the same manner as in Phase I, but for Phase II, we used a transparent plastic divider with $5 \mathrm{~mm}$ holes (which allowed for visual and chemical, but not physical, interaction among all individuals in a given tank) to divide each aquarium in half. None of the BTMs used in the previous phase were used for the conditioning trials (i.e., all fish were naïve to chondroitin). We randomly assigned BTM individuals to one of the following treatments: (1) control: two BTMs, no WMF, distilled water added to aquarium, (2) conditioning: two BTMs, two WMF added to aquarium (separated from BTMs by transparent divider), chondroitin sulfate added. It would have been ideal to have a fully factorial design in which we additionally had a treatment to control for experience with WMF (i.e., a treatment in which only WMF were added to the aquarium) and a treatment in which only chondroitin was added to the aquarium. Because we were working with an endangered species that is bred in limited numbers in captivity, we were unfortunately unable to obtain sufficient numbers of BTM at any given point in time to include all four treatments in a single experiment. However, because we were able to obtain additional fish throughout the year, we were able to assess the effect of chondroitin only (see Phase I methods above) and WMF only (see Phase IV methods below) on BTM behavior in separate experiments. The fact that we were not able to perform a fully factorial experiment is a limitation of our study (see also Discussion).

In the conditioning phase of our study, each replicate began by adding two BTM to the tank and allowing the fish to acclimate for $6-8 \mathrm{~h}$. For the conditioning treatment $(N=11)$, we simultaneously added chondroitin via tubing and two adult WMF to the tank on the side of the divider opposite the BTMs. Specifically, the WMF were first placed in a small container of water and then poured into the tanks. We expected that pairing the aversive stimulus and potential alarm cue (chondroitin sulfate) with WMF would cause BTM to associate WMF with danger. For the control treatment $(N=12)$, we added distilled water to the tank via tubing and poured a small amount of water into the tank on the side opposite the BTM in an attempt to create similar levels of disturbance across both treatments.

\section{Phase Ilb: Does Conditioning Affect BTM Behavior?}

We set up aquaria in the same manner as in the conditioning trials and used the same individual fish from Phase IIa. We tested fish $\sim 24 \mathrm{~h}$ after conditioning for a behavioral response to the visual and chemical presentation of WMF, with no substances added to the tank. This phase of the study allowed us to determine if our conditioning was effective and caused BTM to alter their behavior in response to WMF. We placed two BTMs from the same treatment (conditioned or control) into each tank and allowed them to acclimate for 6-8 h. During an initial $10 \mathrm{~min}$ observational period, we recorded the time that both fish spent in motion. Two adult WMF were then added to the tank on the side of the divider opposite the BTMs, and specifically, WMF were placed in a small container with water and poured into the tank on the side opposite the BTM. In the control treatment, a small amount of water was poured into the tank in a similar manner. We then performed another $10 \mathrm{~min}$ observational period in which we recorded both fish's time spent in motion. We then calculated the combined change in motion for the BTM in that tank and used a Univariate Analysis of Variance to examine the 
effect of conditioning on the change in activity (i.e., change in the proportion of the time the BTM in a tank spent active). To avoid pseudoreplication, each tank (rather than each fish) served as a replicate; that is, our response variable was the change in the proportion of time that all fish in a given tank spent in motion. Treatment (conditioning or control) was a fixed factor with change in activity as the dependent variable. If our conditioning was effective, we expected the change in activity (i.e., the change in the proportion of time spent active) to differ between our two treatments. Fish from each treatment were housed separately until they were used in Phase III of the study. While it would have been ideal to include an additional non-predator control treatment during this testing phase (i.e., a treatment in which BTM were presented with a non-predator) to assess whether BTM developed a response only to WMF or to other fish in general, this was not possible due to limited BTM availability.

\section{Phase III: Release and Recapture: Does Conditioning Improve Survival of BTM?}

After use in behavioral trials, we marked conditioned BTM with visible implant elastomer tags on their left side and control BTM with elastomer tags on their right side. During tagging, each fish was removed from the water, placed onto a damp paper towel, and tagged as quickly as possible before being placed back into a container with water. BTM were tagged within $24 \mathrm{~h}$ of release, which was $\sim 13$ days after lab trials were complete. While tagging was potentially a stressful event, BTM from both treatments experienced this tagging, and substantial time had passed between the presentation of WMF in the conditioning treatment and tagging. Therefore, we think that it is unlikely that BTM in the conditioning treatment would associate the tagging event with the cues of the WMF.

With conditioned and non-conditioned fish marked differently with elastomer tags, and following a negative disease screening by Conservation Fisheries, Inc., we released fish from both treatments ( 22 conditioned and 24 control BTMs) into the wild at the Ramsey Barn site 14 days following conditioning. Three days later, we sampled by seining 20 times for $\sim 4 \mathrm{~h}$ in an attempt to recapture marked fish. As mentioned above, we hypothesized that conditioning BTM to associated WMF with a potential alarm cue would alter BTM behavior and ultimately increase BTM survival. As such, we expected to re-capture more conditioned than unconditioned BTMs.

We used a Chi Squared analysis to determine if conditioned fish were more likely to be recaptured than unconditioned fish. Because our recapture rates were relatively low (presented in Results), we used the Likelihood Ratio test statistic in our ChiSquared analysis, which is the most appropriate Chi-Squared test statistic and is preferred over a Pearson Chi-Squared test when expected values are relatively low (McHugh, 2013). While using Fisher's Exact Test is often ideal when expected values are low, using Fisher's Exact Test was problematic and avoided in our study for the following reasons: (1) a Fisher's Exact Test assumes that the marginal totals in the contingency table are fixed, and given that recapture rate was not fixed or known beforehand in our study, we violated this assumption, and (2) when the fixed variables assumption is violated, Fisher's Exact Test is considered to be overly conservative and is associated with too high of a Type II error rate (Agresti, 2002; Nussbaum, 2014). The ANOVA and Chi-Squared test were performed in SPSS 22.0.

\section{Phase IV: Distinguishing Between the Effects of Experience vs. Conditioning on Behavior}

Because the design outlined in Phases I and II above did not allow us to determine whether experience with WMF or conditioning affected BTM behavior, we performed a second, small-scale follow-up behavioral experiment when additional fish became available for behavioral trials in which we compared the behavior of BTM that had been exposed to either: (1) only distilled water (Control 1), (2) two WMF paired with distilled water (Control 2), and (3) two WMF paired with chondroitin sulfate. This allowed us to determine if experience alone with WMF or conditioning (i.e., pairing an aversive stimulus, the alarm cue chondroitin sulfate, with the presentation of WMF) led to the behavioral changes that we observed in Phase II above. All methods, including analyses, in this follow-up experiment were identical to those outlined in Phase IIa and IIb above, with the exception of the additional treatment (Control 2). No fished used in Phase IV had been used previously in this study.

\section{RESULTS}

\section{BTMs Respond to Chondroitin}

There was a significant difference between the BTM's response to the addition of the control substance (distilled water) and the addition of chondroitin $\left(F_{1,17}=6.72, P=0.020\right)$. Specifically, chondroitin significantly decreased activity in the BTM with a mean $( \pm \mathrm{SE})$ change in proportion of time active of -0.21 $( \pm 0.087)$ following the addition of chondroitin. Control fish exhibited a mean $( \pm \mathrm{SE})$ change in proportion of time active of $0.00035( \pm 0.027)$ following the addition of distilled water. While additional research would be needed to determine whether chondroitin is a natural alarm cue in this species (discussed further below), our results importantly suggest that chondroitin affects BTM behavior and can potentially act as an aversive stimulus in BTM.

\section{Conditioning Affects BTM Response to the Novel Predator}

BTM can be conditioned to alter their behavioral response to the novel predator, WMF. There was a significant difference between the response of conditioned fish to WMF and the response of the control group to $\operatorname{WMF}\left(F_{1,21}=4.397, P=0.048\right.$; Figure 1). Specifically, fish that were conditioned to associate WMF with the aversive stimulus chondroitin sulfate increased activity $\sim 2$-fold in the presence of WMF relative to unconditioned fish (Figure 1).

\section{Conditioning Has the Potential to Improve BTM Survival}

As mentioned above, we released 22 control and 24 conditioned BTMs into a natural spring habitat following conditioning. 


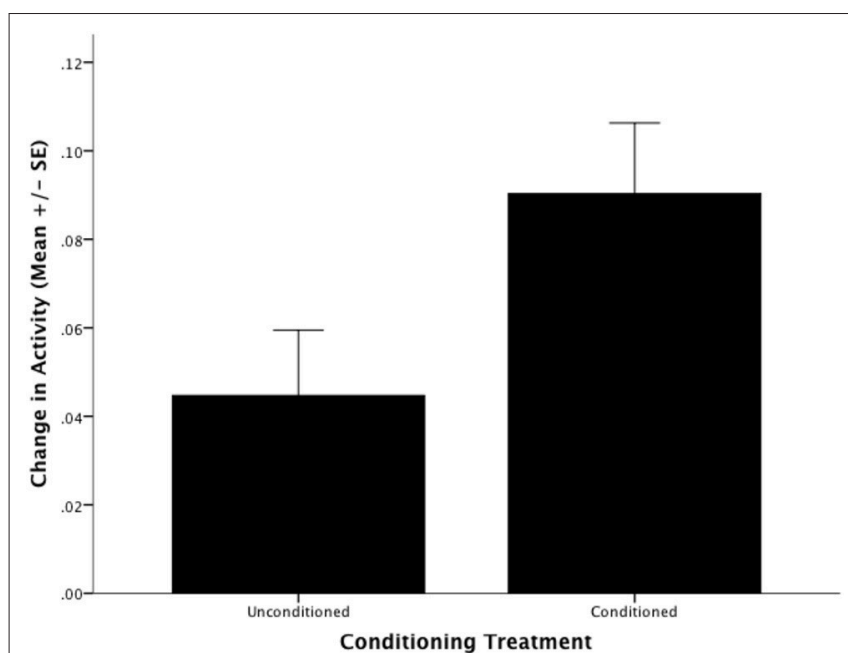

FIGURE 1 | The Barrens Topminnows (Fundulus julisia) can be conditioned to alter their behavior in response to a novel predator. Change in the proportion of time spent in motion by Barrens Topminnows before and after presentation of Western Mosquitofish (Gambusia affinis) for unconditioned and conditioned treatments (whiskers represent \pm standard error).

A total of three marked fish from this study were recaptured, with all three identified as conditioned fish. This represented a significant difference between expected and observed recapture rates for the two groups $\left(\chi^{2}=4.1, \mathrm{df}=1, P=0.04\right)$, suggesting that it is unlikely that we recaptured more conditioned than unconditioned fish due to chance. While the pattern of recapturing more conditioned than unconditioned fish is what we would expect if conditioned fish were more likely to survive than unconditioned fish, it is important to note that these findings are based on very small sample sizes, and as such, it is unclear if these findings are repeatable across contexts or studies. Additional replication would be needed to confirm this pattern of re-capture.

\section{Conditioning, Rather Than Experience Alone, Led to Behavioral Changes}

Conditioning (i.e., exposure to WMF and chondroitin) caused BTM to increase activity when they were subsequently presented with only WMF relative to both control treatments (ANOVA, treatment effect on arc sine square root transformed data to meet assumptions of normality: $F_{2,31}=3.33, p=0.049$; Figure 2). This finding is consistent with the patterns found in the Phase II of the study. Specifically, BTM who had been conditioned to associate the alarm cue with WMF increased activity more than fish that were unconditioned (Control 1) or that had experience with WMF (Control 2) (Figure 2). Such a pattern might suggest that conditioning, rather than experience alone, led to the behavioral differences observed in Phase II of our study.

\section{DISCUSSION}

The detrimental effect of introduced species is a major conservation concern, particularly in regard to the long-term

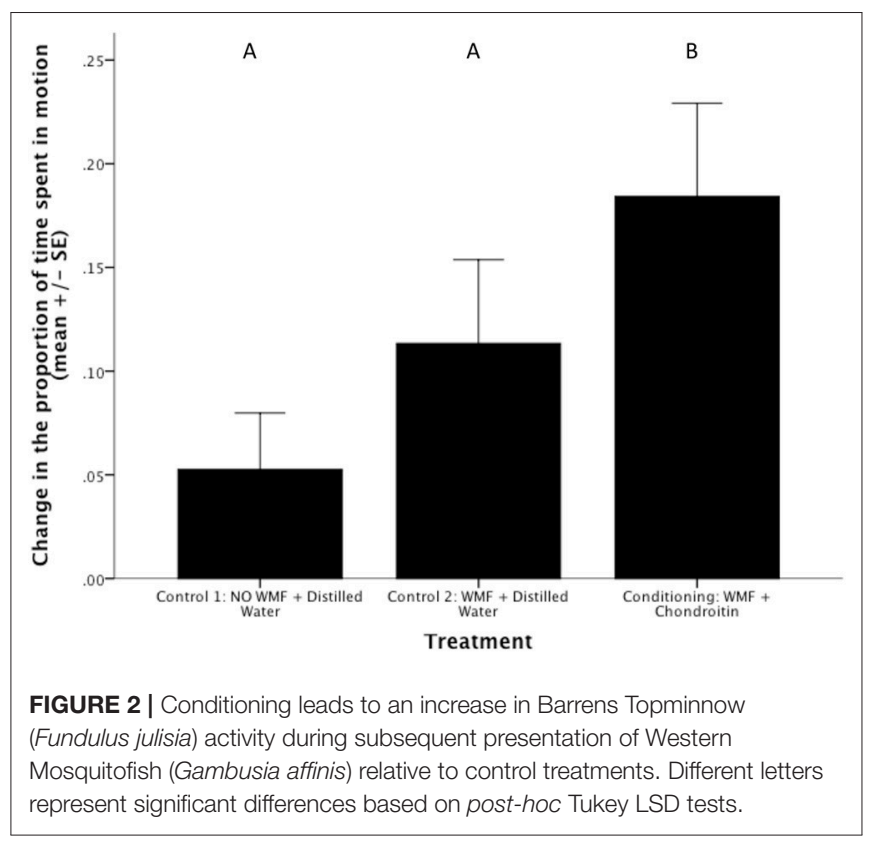

persistence of endangered species (Schlaepfer et al., 2002). Here, we have shown that learning can potentially be used to alter juvenile behavior in an ecologically relevant way and potentially mitigate the negative effects of an introduced species. In particular, our work illustrates that conditioning individuals to associate an introduced predator with an aversive stimulus can elicit behavioral changes that might improve survival. Further, our follow-up work (Figure 2) demonstrates that the behavioral changes observed are most likely due to conditioning and not simply experience with WMF, which might explain why wild BTM, who naturally gain experience with WMF, have been unable to effectively alter their behavior when faced with WMF in nature. Further, BTM that were conditioned to associate the introduced predator WMF with the potential alarm cue chondroitin sulfate were more likely to be re-captured after release into the wild than unconditioned fish, potentially suggesting that they had higher survival than unconditioned fish. This finding suggests that conditioning can potentially be used to improve survival of native individuals. Indeed, the finding that conditioning can alter the behavioral response to a predator is consistent with work done in other species (Herzog and Hopf, 1984; Maloney and McLean, 1995; Shier and Owings, 2006; O'Donnell et al., 2010). Likewise, the finding that conditioning has the potential to improve survival is consistent with research done in other contexts (Mirza and Chivers, 2000, 2003; Gazdewich and Chivers, 2002).

Importantly, the sample sizes of our study were small and our assessment of survival was conducted over a relatively short time frame and only at one point in time following the release of fish into the wild. The low sample sizes are a limitation of our study; given this, it will be particularly important to expand upon this work in the future to determine how repeatable our findings are with additional fish and across a longer time period. However, it is still noteworthy that all recaptured individuals from this 
project were those that were conditioned to associate WMF with a potential alarm cue, and this is especially relevant considering the high density of WMF at the site. Indeed, recapturing small fish in a large spring site is inherently challenging, and as such recapturing any of our marked fish was somewhat unexpected. We therefore view the fact that only conditioned fish were recaptured as intriguing and striking, and we suggest that more work is needed that examines the role of learning in relation to overcoming a lack of evolutionary history in the face of environmental change. In particular, in order to fully mitigate the negative effects of introduced species, successful BTM reproduction and recruitment would be needed (i.e., the reintroduced population would have to become self-sustaining). Indeed, it is likely that reintroduction efforts for this species have had relatively little impact because the released BTM get consumed by WMF before having much of an opportunity to learn socially in their natural habitat. As such, examining whether social learning occurs when a small number of fish have been conditioned is a key next step.

In the future, it will also be important to examine if conditioning causes BTM to react only to WMF, or if the conditioned response is generalized to other fish, including other potential predators and non-predators. This could be examined by including additional treatments in the test phase of our conditioning trials (Phase II b above) in which BTM are presented with fish other than WMF. Such a study would (1) inform us of whether conditioning is likely to be generalizable to a range of predators and (2) provide insight into the dynamics of learning in fish by identifying whether the effects of conditioning are specific to predators or a range of fish species.

In addition to demonstrating a potential role for conditioning in mitigating the effects of an introduced species, our study also revealed that the potential alarm cue chondroitin sulfate affects behavior and reduces activity in the BTM. As a topwater prey species living near vegetation, freezing is likely one adaptive antipredator behavior (Reed, 1969; Farnsley et al., 2016). The finding that chondroitin sulfate potentially functions as an alarm cue is consistent with work done in other species (Mathuru et al., 2012; Farnsley et al., 2016). However, given our experimental design, additional work is needed to determine if chondroitin sulfate is a natural alarm cue in BTM. Specifically, in the portion of the study in which we examined the effect of chondroitin sulfate on BTM behavior, we had two treatments: one in which BTM were exposed to chondroitin sulfate and a second treatment in which fish were exposed to distilled water. It would have been ideal to include a third treatment in which BTM were exposed to the skin extracts from conspecifics, as this would have functioned as a positive control to determine if chondroitin elicits a response that is comparable to the response that would occur if BTM are exposed to the skin extracts of injured conspecifics. Unfortunately, this was not possible due to limited BTM numbers and animal care concerns related to the endangered status of BTM. As such, it is important to note that further work is needed to determine whether chondroitin sulfate elicits a behavioral response that is similar to the behavioral changes that would occur in response to the skin extracts of an injured conspecific.

Conditioning BTMs to associate the predator WMF with chondroitin affected their response to WMF. Compared to control BTMs, conditioned BTMs had roughly twice an increase in activity as the control fish when WMF was presented. Because our first experiment showed that addition of chondroitin alone caused a decrease in activity in BTM, it is interesting that conditioning that paired the alarm cue and the predator caused increased activity. This difference in response (i.e., increased vs. decreased activity) could be due to the different levels of threat posed by the two different phases of the experiment (Helfman, 1989). As only one identified component of the known alarm substance in Zebrafish, chondroitin sulfate may elicit a weaker antipredator behavior in the BTM as compared to chondroitin coupled with the visual and chemical presence of two nearby predators. Also, the BTM's increased activity in the presence of WMF could be attributed to predator-inspection behavior, which has been documented in many fish species and other taxa as well (e.g., Brown et al., 2001).

In summary, our study illustrates that conditioning may allow for juvenile BTM to overcome a lack of evolutionarily engrained anti-predator responses and learn to recognize WMF as a potential predator, and this in turn might improve survival of the imperiled BTM in its natural habitat. More generally, it may be possible for a range of organisms to overcome a lack of evolutionarily engrained adaptive responses by means of conditioning. In this case, we were the teachers, but an organism's natural habitat also provides opportunities for learning, and learning might play a larger role in acclimating to environmental change than is currently appreciated (see also discussion in Greggor et al., 2014).

\section{AUTHOR CONTRIBUTIONS}

All authors contributed to the design of the study and revisions of the manuscript. SF took the lead on data collection, data analyses, and manuscript preparation.

\section{ACKNOWLEDGMENTS}

We are grateful to: Conservation Fisheries Inc. and Patrick Rakes for providing fish, Tennessee Wildlife Resources Agency and Brad Bingham for assisting with fish capture and site access, the Ramsey family for allowing us access to their spring, and Stephanie Sisson, Holly Prince, Tosin Ayotunde, Anna Claire Robinson, Wil Pope, Cooper Thorne and Ken Gentner for data collection. The work presented herein served as part of the M.S. thesis of SF (Farnsley, 2014). Funding was provided by a UTC Provost Student Research Award to SF and a UTC Faculty Research Grant and UTC Engaged Grant to HK. A portion of this material is based upon work supported by the National Science Foundation under Grant No. 1552721 to $\mathrm{HK}$. 


\section{REFERENCES}

Agresti, A. (2002). Categorical Data Analysis. Hoboken, NJ: Wiley and Sons.

Barnosky, A. D., Matzke, N., Tomiya, S., Wogan, G. O., Swartz, B., Quental, T. B., et al. (2011). Has the Earth's sixth mass extinction already arrived? Nature 471, 51-57. doi: 10.1038/nature09678

Bettoli, P. W. (2015). The last stand of the Barrens Topminnow. Fisheries 40, 102-103. doi: 10.1080/03632415.2015.1006324

Brown, G. E., Golub, J. L., and Plata, D. L. (2001). Attack cone avoidance during predator inspection visits by Wild Finescale Dace (Phoxinus neogaeus): the effects of predator diet. J. Chem. Ecol. 27, 1657-1666. doi: 10.1023/A:1010466410152

Buchholz, R. (2007). Behavioural biology: an effective and relevant conservation tool. Trends Ecol. Evol. 22, 401-407. doi: 10.1016/j.tree.2007.06.002

Farnsley, S. E. (2014). Overcoming Evolutionary History: Conditioning the Endangered Barrens Topminnow to Avoid Predation by the Invasive Western mosquitofish. Master's thesis. Chattanooga, TN: University of Tennessee at Chattanooga.

Farnsley, S. E., Kuhajda, B., George, A., and Klug, H. (2016). Northern Studfish (Fundulus catenatus) response to the alarm cue chondroitin sulfate. Southeast. Nat. 15, 523-533. doi: 10.1656/058.015.0315

Gazdewich, K. J., and Chivers, D. P. (2002). Acquired predator recognition by fathead minnows: influence of habitat characteristics on survival. J. Chem. Ecol. 28, 439-445. doi: 10.1023/A:1017902712355

Goldsworth, C. A., and Bettoli, P. W. (2006). Growth, body condition, reproduction and survival of stocked Barrens Topminnows, Fundulus julisia (Fundulidae). Am. Midl. Nat. 156, 331-343. doi: 10.1674/00030031(2006)156[331:GBCRAS]2.0.CO;2

Greggor, A. L., Clayton, N. S., Phalan, B., and Thornton, A. (2014). Comparative cognition for conservationists. Trends. Ecol. Evol. 29, 489-495. doi: $10.1016 / j$.tree.2014.06.004

Halpern, B. S., Walbridge, S., Selkoe, K. A., Kappel, C. V., Micheli, F., D’Agrosa, C., et al. (2008). A global map of human impact on marine ecosystems. Science 319, 948-952 doi: 10.1126/science.1149345

Helfman, G. S. (1989). Threat-sensitive predator avoidance in damselfish-trumpetfish interactions. Behav. Ecol. Sociobiol. 24, 47-58. doi: $10.1007 /$ BF00300117

Herzog, M., and Hopf, S. (1984). Behavioral responses to species-specific warning calls in infant squirrel monkeys reared in social isolation. Am. J. Primatol. 7, 99-106. doi: 10.1002/ajp.1350070204

Kiesecker, J. M., and Blaustein, A. R. (1997). Population differences in responses of red-legged frogs (Rana aurora) to introduced bullfrogs. Ecology 78, 1752-1760. doi: 10.1890/0012-9658(1997)078[1752:PDIROR]2.0.CO;2

Kotiaho, J. S., Kaitala, V., Komonen, A., and Päivinen, J. (2005). Predicting the risk of extinction from shared ecological characteristics. Proc. Natl. Acad. Sci. U.S.A. 102, 1963-1967. doi: 10.1073/pnas.0406718102

Maloney, R. F., and McLean, I. G. (1995). Historical and experimental learned predator recognition in free-living New Zealand Robins. Anim. Behav. 50, 1193-1201. doi: 10.1016/0003-3472(95)80036-0

Manassa, R. P., and McCormick, M. I. (2012). Social learning and acquired recognition of a predator by a marine fish. Anim. Cogn. 15, 559-565. doi: 10.1007/s10071-012-0484-z

Mathuru, A. S., Kibat, C., Cheong, W. F., Shui, G., Wenk, M. R., Friedrich, R. W., et al. (2012). Chondroitin fragments are odorants that trigger fear behavior in fish. Curr. Biol. 22, 538-544. doi: 10.1016/j.cub.2012.01.061

McHugh, M. (2013). The Chi-square test of independence. Biochem. Med. 23:143-149. doi: 10.11613/BM.2013.018

Mirza, R., and Chivers, D. (2000). Predator-recognition training enhances survival of brook trout: evidence from laboratory and field-enclosure studies. Can. J. Zool. 78, 2198-2208. doi: 10.1139/z00-164
Mirza, R., and Chivers, D. (2003). Response of juvenile rainbow trout to varying concentrations of chemical alarm cue: response thresholds and survival during encounters with predators. Can. J. Zool. 81, 88-95. doi: 10.1139/z 02-216

Mooney, H. A., and Hobbs, R. J. (2000). Invasive Species in a Changing World. Washington, DC: Island Press.

Novacek, M. J. (2001). The Biodiversity Crisis: Losing What Counts. New York, NY: The New Press.

Novacek, M. J., and Cleland, E. E. (2001). The current biodiversity extinction event: scenarios for mitigation and recovery. Proc. Natl. Acad. Sci. U.S.A. 98, 5466-5470. doi: 10.1073/pnas.091093698

Nussbaum, E. M. (2014). Categorical and Nonparametric Data Analysis: Choosing the Best Statistical Technique. Hoboken, NJ: Taylor and Francis.

O'Donnell, S., Webb, J. K., and Shine, R. (2010). Conditioned taste aversion enhances the survival of an endangered predator imperilled by a toxic invader. J. Appl. Ecol. 47, 558-565. doi: 10.1111/j.1365-2664.2010.01802.x

Phillips, B. L., and Shine, R. (2006). An invasive species induces rapid adaptive change in a native predator: cane toads and black snakes in Australia. Proc. $R$. Soc. B 273, 1545-1550. doi: 10.1098/rspb.2006.3479

Pimentel, D., Zuniga, R., and Morrison, D. (2005). Update on the environmental and economic costs associated with alien-invasive species in the United States. Ecol. Econom. 52, 273-288. doi: 10.1016/j.ecolecon.2004.10.002

Rakes, P. L. (1989). Life History and Ecology of the Barrens Topminnow, Fundulus julisia Williams and Etnier (Pisces, Fundulidae). Knoxville, TN: University of Tennessee.

Reed, J. R. (1969). Alarm substances and fright reaction in some fishes from the southeastern United States. T. Am. Fish. Soc. 4, 664-668. doi: 10.1577/15488659(1969)98[664:ASAFRI]2.0.CO;2

Robertson, B. A., Rehage, J. S., and Sih, A. (2013). Ecological novelty and the emergence of evolutionary traps. Trends Ecol. Evol. 28, 552-560. doi: 10.1016/j.tree.2013.04.004

Schlaepfer, M. A., Runge, M. C., and Sherman, P. W. (2002). Ecological and evolutionary traps. Trends Ecol. Evol. 17, 474-480. doi: 10.1016/S0169-5347(02)02580-6

Schlaepfer, M. A., Sherman, P. W., Blossey, B., and Runge, M. C. (2005). Introduced species as evolutionary traps. Ecol. Lett. 8, 241-246. doi: 10.1111/j.1461-0248.2005.00730.x

Shier, D. M., and Owings, D. H. (2006). Effects of predator training on behavior and post-release survival of captive prairie dogs (Cynomys ludovicianus). Biol. Conss 132, 126-135. doi: 10.1016/j.biocon.2006.03.020

Sih, A., Ferrari, M. C., and Harris, D. J. (2011). Evolution and behavioural responses to human-induced rapid environmental change. Evol. Appl. 4, 367-387. doi: 10.1111/j.1752-4571.2010.00166.x

Vitousek, P. M., Mooney, H. A., Lubchenco, J., and Melillio, J. M. (1997). Human domination of Earth's ecosystems. Science 277, 494-499.

Wong, B. B. M., and Candolin, U. (2015). Behavioral responses to changing environments. Behav. Ecol. 26, 665-673. doi: 10.1093/beheco/a ru183

Conflict of Interest Statement: The authors declare that the research was conducted in the absence of any commercial or financial relationships that could be construed as a potential conflict of interest.

Copyright () 2018 Farnsley, Kuhajda, George and Klug. This is an open-access article distributed under the terms of the Creative Commons Attribution License (CC BY). The use, distribution or reproduction in other forums is permitted, provided the original author(s) and the copyright owner(s) are credited and that the original publication in this journal is cited, in accordance with accepted academic practice. No use, distribution or reproduction is permitted which does not comply with these terms. 